\title{
EVALUATION OF BRUXISM AND ITS RELATION WITH TREATMENT REGIMENS AMONG REMITTED BIPOLAR PATIENTS
}

\author{
Özlem Gurbuz Oflezer ${ }^{1}$, Hakan Bahadır ${ }^{2}$, Berna Gökkaya ${ }^{3}$ \& Kursat Altinbas ${ }^{4}$ \\ ${ }^{1}$ Department of Prosthodontics, Ministry of Health of Turkey, Bahcelievler Oral and Dental Hospital, Istanbul, Turkey \\ ${ }^{2}$ Department of Radiology, Private Practice, Bahçelievler/İstanbul, Turkey \\ ${ }^{3}$ Department of Pediatric Dentistry, Ministry of Health of Turkey, Bahcelievler Oral and Dental Hospital, \\ Istanbul, Turkey \\ ${ }^{4}$ Department of Psychiatry, Selcuk University Faculty of Medicine, Konya, Turkey
}

received: 30.12.2019;

revised: 17.3.2020;

accepted: 8.4.2020

\section{SUMMARY}

Background: The aim of this study was to evaluate the association of bruxism and treatment regimens among remitted bipolar patients. Subjects and methods: The total case group included 222 adult patients with BD. Diagnosis of bruxism was based upon the on 'self-reports' plus the outcome from the clinical examinations.

Results: The sample consisted of 112 (50.5\%) bipolar patients with bruxism and 110 (49.5\%) without bruxism. Remitted bipolar patients who were on mood stabilizer plus atypical antipsychotic treatment had lower bruxism rates than patients on other than bipolar patients on mood stabilizer treatment regimen $(p=0.04)$ and bipolar patients on polypharmacy $(p=0.01)$.

Conclusion: Our findings have supported the existence of psychotropic drug-bruxism relation and atypical antipsychotic related therapeutic effect among bipolar patients.

Key words: bipolar disorder - bruxism - treatment regimens

\section{INTRODUCTION}

Bruxism is a repetitive jaw muscle activity characterized by clenching or grinding of the teeth and/or by bracing or thrusting of the mandible that can occur during wakefulness (i.e. awake bruxism) or during sleep (i.e. sleep bruxism) (Lobbezzoo et al. 2013). A consistent amount of literature suggests that peripheral factors play a minor role in the etiopathogenesis of bruxism (Kato et al. 2003, Manfredini et al. 2004, Manfredini et al. 2005), while central nervous systemrelated mediators seem to have much more importance (Lobbezoo \& Naeije 2001, Lavigne et al. 2003), and, therefore, probably to have an intrinsic relationship with mental disorders. Several studies showed a high frequency of psychiatric patients who suffered from temporomandibular disorder signs and tooth wear (Winocur et al. 2007, Gurbuz et al. 2009, Gurbuz et al. 2017, Piccoli et al. 2014, Kinalski et al. 2019). The medical specialists should be aware of the effect of mental disorders and their treatment on oral health as well as of the effect of oral/dental disorders on mental health and treatment outcome in psychiatry. Authors strongly emphasize the need for more collaboration in order to bridge the professional gap between dentistry and psychiatry (Sarac et al. 2020). Psychiatric literature seems to suggest that bipolar patients are characterized by disturbances in the central neurotransmitter system (Craddock et al. 2001), which may also be involved in the etiology of bruxism (Lobbezzoo et al. 1997). Authors suggested that one of the possible hypotheses explaining the association between bruxism and mood disorders may be drawn from studies on neurotransmitter systems that are influenced by medications (Winocur et al. 2003, Su Y\& Sinko 2006). Despite some possible common neurological alterations were described in bruxers and bipolar patients (Lavigne et al. 2003, Lobbezoo et al. 1997, Craddock et al. 2001) only one pilot work (Manfredini et al. 2004) investigated for possible clinical associations between such disorders. Based on the hypothesis that dopaminergic system disorders might represent a shared pathogenetic pathway for both bruxism and bipolar psychopathology, authors investigated the prevalence of manic depressive disorders in bruxers, showing an association between mood disorders and anamnestically diagnosed bruxism and also pointing out some interesting aspects concerning a possible relation with manic symptoms (Manfredini et al. 2004). The findings from another investigation suppor ted the existence of an association between bruxism and mood disorders or psychopathology has been confirmed (Manfredini et al. 2005). In additition to, we previously also showed that bipolar patients have a significantly higher possible bruxism prevalence than mentally healthy control subjects (Gurbuz et al. 2017). To date, there are no studies investigating the influence of treatment regimens on bruxism among bipolar patients. Hence, we hypothesized that the significant associations of the different variables among remitted bipolar patients would be found between bruxers and non-bruxers, and tested this hypothesis in a group of bipolar patients from the study of Gurbuz et al. (2017). 


\section{SUBJECTS AND METHODS}

The Medical Ethics Committee of Bakırköy Research and Training Hospital for Psychiatry, Neurology, and Neurosurgery approved the study protocol, and the study was carried out in accordance with the Declaration of Helsinki. Written informed consent was obtained from all the participants prior to enrollment. Subjects came from the study of Gurbuz et al. (2017) and further details of the sample and methods can be found in the original report. In brief, we made the diagnosis of bruxism was based on history and clinical assessment. Out of the 222 included bipolar patients, 112 had bruxism, 110 had not, and these were seperated into two groups. The two groups have been compared in age, gender, education, marital status, use of alcohol and tobacco, average number of episodes, first episode, disease time and treatment time, electroconvulsive treatment, presence of pychiatric diseases in relatives, and treatment protocols. The bipolar group has been divided to three categories depending on use of mood stabilizers (MS) only, atypical antipsychotic (AAP) in addition to mood stabilizers, and on use of MS and AAP, typical antipsychotic (TAP), depot antipsychotic (DAP) additional use of antidepressant (AD) i.e.polypharmacy. Statistical analysis was performed with NCSS (Number Cruncher Statistical System) 2007 (NCSS LLC; Kaysville, Utah, USA). The normal distribution of quantitative data was tested with the Shapiro-Wilk test and graphical investigations. For quantitative data normal distribution, the comparison of avarage values of measurements taken from the two groups was carried out independent t test. For quantitative data lacking normal distribution, nonparametric Mann-Whitney test was used for the comparison of medians. The strength of the association between qualitative variables was analysed using Pearson's chisquared test and the Fisher-Freeman-Halton test. Level of significance was set at $\mathrm{p}<0.05$.

\section{RESULTS}

In statistical analysis, in between patients in remission with and without bruxism, no logical difference were found to cause bruxism in demographical and clinical variances, except treatment protocols (Table 1). Treatment protocols were analysed under three categories as usage of one or more MS, usage of MS with AAP; polypharmacy with at least three different drug categories as MS, AP (TAP and/or AAP and/or DAP) and $\mathrm{AD}$ (Table 1). It has been found that patients using AAP with MS has less risk of bruxism than MS monotheraphy $(\mathrm{p}=0.04)$ and polypharmaceutical theraphy $(\mathrm{p}=0.01)$ (Table 1).

\section{DISCUSSION}

The high prevalence of bruxism in bipolar patients represents a challenge for clinical dentistry, as it can cause impairment of the masticatory structures. In this study, subjects with BD from MS+AAP treatment group showed significantly lower presence of bruxism than the other two groups. AP drugs are DA antagonists (Meltzer $\&$ Massey 2011) and reduce the activity of the dopaminergic pathways by blocking the DA receptors. The so-called TAP exert their effects by antagonizing the D2 DA receptors of the brain's DA pathways. AAP do not only block the D2 receptor but also block the 5HT2A and 5-HT1A receptors. As for the DA agonists, these drugs may induce or suppress bruxism as a consequence of their side effects to the DA and/or 5-HT pathways (Meltzer \& Massey 2011). It appears that AAP drugs, which antagonize both DA and 5-HT receptors, are successful in treating bruxism (Mendhekar \& Andrade 2009, Shiwach \&Woods 1998). The therapeutic mechanism of these drugs is not known but may be in part explained by the fact that these AAP drugs have been developed with the attempt to reduce extrapyramidal side effects and possess a lower affinity to the DA receptors and by the fact that these AAP drugs also antagonize the 5-HT receptors may also contribute to explain their therapeutic effects (Fallisi et al. 2014). Selective DA antagonists, such as typical antipsycho tics, antagonize the DA receptors in the same DA pathway causing dysfunction of motor control and phenomena of tardive dyskinesia and bruxism. Drugs inhibiting the serotonergic neurotransmission, such as atypical antipsychotics, suppress bruxism by the inverse mechanism, normalizing the activity of the mesocortical pathway. Altogether, these studies suggest that regional differences in DA receptor pharmacology may be the cause of the confusion generated by the occurrence of bruxism in both hyper- and hypodopaminergic states (Pelayo \& Yuen 2012). Findings suggest that the relation between dopaminergic drugs and bruxism may be complex because of multiple DArelated circuits, which, if altered in one or the other direction, may provoke or suppress bruxism (Fallisi et al. 2014).

Due to the fact that there might be the possibility that the AAPs can treat or correct the existing bruxism through 5HT2A, in addition, because AAPs have been proven to be effective in both the depression period and the manic period and as a result can now be suggested as MS, it can be argued that because they correct the dopaminergic and serotonergic function disruption in the common etiologic pathway, AAPs can also decrease bruxism or cause it to be seen less frequently. It has been discussed by various researchers that with lithium and lamotrigine treatment, there can be an emergence of bruxism symptoms and that the AP added to the treatment can improve these symptoms; however, the reason for this observed improvement has not been explained (Mc Meekin et al. 2007). The results of this study supports that atypical antipsychotics do not have any negative effects on the bipolar patients with bruxism and even that they might have therapeutic effects. 
Table 1. Comparisons of the clinical and demographic characteristics of bipolar patients with and without bruxism

\begin{tabular}{|c|c|c|c|c|c|}
\hline Data & Explanation & Total & $\begin{array}{l}\text { Bipolar Patients } \\
\text { without Bruxism }\end{array}$ & $\begin{array}{l}\text { Bipolar Patients } \\
\text { with Bruxism }\end{array}$ & $\mathrm{P}$ value \\
\hline Age & $\begin{array}{l}\text { Mean } \pm \text { Standard deviation } \\
\text { Min-Max (Median) }\end{array}$ & $\begin{array}{c}34.49 \pm 9.62 \\
18-63(34)\end{array}$ & $\begin{array}{c}34.48 \pm 9.11 \\
20-61(33.59)\end{array}$ & $\begin{array}{c}36.47 \pm 10.4 \\
18-63(35.5)\end{array}$ & $0.123^{a}$ \\
\hline Gender $(\%)$ & $\begin{array}{c}\text { Male } \\
\text { Female }\end{array}$ & $\begin{array}{r}97(43.7) \\
125(56.3)\end{array}$ & $\begin{array}{l}52(47.3) \\
58(52.7)\end{array}$ & $\begin{array}{l}45(40.2) \\
67(59.8)\end{array}$ & $0.287^{\mathrm{b}}$ \\
\hline Education level (\%) & $\begin{array}{l}\text { Primary } \\
\text { High School } \\
\text { University }\end{array}$ & $\begin{array}{c}88(39.6) \\
74(33.3) \\
60(27)\end{array}$ & $\begin{array}{l}43(39.1) \\
36(32.7) \\
31(28.2)\end{array}$ & $\begin{array}{l}45(40.2) \\
38(33.9) \\
29(25.9)\end{array}$ & $0.929^{b}$ \\
\hline Marriage (\%) & $\begin{array}{l}\text { Single } \\
\text { Married } \\
\text { Divorce }\end{array}$ & $\begin{array}{l}114(51.4) \\
89(40.1) \\
19(8.6)\end{array}$ & $\begin{array}{c}61(55.5) \\
41(37.3) \\
8(7.3)\end{array}$ & $\begin{array}{c}53(47.3) \\
48(42.9) \\
11(9.8)\end{array}$ & $0.457^{b}$ \\
\hline Duration of disorder & $\begin{array}{l}\text { Mean } \pm \text { Standard deviation } \\
\text { Min-Max (Median) }\end{array}$ & $\begin{array}{c}13.29 \pm 7.81 \\
1-42(12)\end{array}$ & $\begin{array}{l}12.86 \pm 7.41 \\
1-36(12)\end{array}$ & $\begin{array}{l}13.71 \pm 8.19 \\
1-42(12.5)\end{array}$ & $0.423^{\mathrm{a}}$ \\
\hline Duration of treatment & $\begin{array}{l}\text { Mean } \pm \text { Standard deviation } \\
\text { Min-Max (Median) }\end{array}$ & $\begin{array}{l}11.48 \pm 7.5 \\
0-42(10)\end{array}$ & $\begin{array}{l}11.66 \pm 7.63 \\
1-36(10)\end{array}$ & $\begin{array}{l}11.3 \pm 7.4 \\
0-42(10)\end{array}$ & $0.721^{\mathrm{a}}$ \\
\hline Total episode (\%) & $\begin{array}{l}\text { Mean } \pm \text { Standard deviation } \\
\text { Min-Mak (Median) }\end{array}$ & $\begin{array}{c}6.68 \pm 4.92 \\
1-35(6)\end{array}$ & $\begin{array}{l}6.42 \pm 4.65 \\
1-30(6)\end{array}$ & $\begin{array}{c}6.95 \pm 5.17 \\
1-35(6)\end{array}$ & $0.448^{d}$ \\
\hline First episode (\%) & $\begin{array}{c}\text { Depression } \\
\text { Mania-hypomania } \\
\text { Mixed } \\
\text { Other } \\
\text { Undifferentiated }\end{array}$ & $\begin{array}{c}97(43.7) \\
107(48.2) \\
3(1.4) \\
5(2.3) \\
10(4.5)\end{array}$ & $\begin{array}{l}49(44.5) \\
55(50) \\
1(0.9) \\
3(2.7) \\
2(1.8)\end{array}$ & $\begin{aligned} 48 & (42.9) \\
52 & (46.4) \\
2 & (1.8) \\
2 & (1.8) \\
8 & (7.1)\end{aligned}$ & $0.386^{\mathrm{c}}$ \\
\hline $\begin{array}{l}\text { History of electrocon- } \\
\text { vulsive theraphy }(\%)\end{array}$ & $\begin{array}{l}\text { Absent } \\
\text { Present }\end{array}$ & $\begin{array}{l}159(71.6) \\
63(28.4)\end{array}$ & $\begin{array}{l}77(70) \\
33(30)\end{array}$ & $\begin{array}{l}82(73.2) \\
30(26.8)\end{array}$ & $0.595^{b}$ \\
\hline Smoking $(\%)$ & $\begin{array}{l}\text { Absent } \\
\text { Present }\end{array}$ & $\begin{array}{l}103(46.4) \\
119(53.6)\end{array}$ & $\begin{array}{l}48(43.6) \\
62(56.4)\end{array}$ & $\begin{array}{l}55(49.1) \\
57(50.9)\end{array}$ & $0.414^{b}$ \\
\hline Alcohol (\%) & $\begin{array}{l}\text { Absent } \\
\text { Present }\end{array}$ & $\begin{array}{c}203(91.4) \\
19(8.6)\end{array}$ & $\begin{array}{l}101(91.8) \\
9(8.2)\end{array}$ & $\begin{array}{c}102(91.1) \\
10(8.9)\end{array}$ & $0.842^{b}$ \\
\hline $\begin{array}{l}\text { History and type of } \\
\text { illness in relatives }\end{array}$ & $\begin{array}{c}\text { Absent } \\
\text { Bipolar Disorder } \\
\text { Schizophrenia } \\
\text { Other } \\
\text { Undifferentiated }\end{array}$ & $\begin{array}{l}85(38.3) \\
91(41) \\
16(7.2) \\
14(6.3) \\
16(7.2)\end{array}$ & $\begin{array}{c}45(40.9) \\
47(42.7) \\
7(6.4) \\
5(4.5) \\
6(5.5)\end{array}$ & $\begin{array}{c}40(35.7) \\
44(39.3) \\
9(8) \\
9(8) \\
10(8.9)\end{array}$ & $0.597^{\mathrm{b}}$ \\
\hline Treatment regimens & $\begin{array}{c}\mathrm{MS}+\mathrm{AAP} \\
\mathrm{MS} \\
\mathrm{MS}+\mathrm{AP}+\mathrm{AD} \text { (Polypharmacy) }\end{array}$ & $\begin{array}{l}150(67.6) \\
46(20.7) \\
26(11.7)\end{array}$ & $\begin{array}{c}84(76.4) \\
18(16.4) \\
8(7.3)\end{array}$ & $\begin{array}{l}66(58.9) \\
28(25.0) \\
18(16.1)\end{array}$ & $0.017^{\mathrm{b}}$ \\
\hline
\end{tabular}

${ }^{\mathrm{a}}$ Independent $\mathrm{t}$ test; ${ }^{\mathrm{b}}$ Pearson ki-kare test; ${ }^{\mathrm{c}}$ Fisher-Freeman-Halton exact test; ${ }^{\mathrm{d}}$ Mann Whitney U test

Lithium, which has been used most frequently in this study, appears as the first-choice drug in both the entire treatment guide and in bipolar manic process and prophylaxis (Fountoulakis et al. 2008). Lithium related tremor is the most frequent of the drug related tremors (Morgan \& Sethi 2005). In this study, the fact that the frequency of bruxism in bipolar patients in the MS groups was significantly higher than the bipolar patients using the MS and AAP drug combination presents the question of whether it is related to the therapeutic mechanisms of the AAPs, the decrease of psychological stress due to the treatment protocol, the influence or effect of direct single use of MS or the receptors and/or neurotransmitter systems. The group of subjects being administered MS and AP in addition to $\mathrm{AD}$, ie polypharmacy, showed significantly higher values than that of the MS and AAP group for the presence of bruxism while awake or sleeping. Bruxism may be exacerbated by selective 5 -HT reuptake inhibitors through an increase in the inhibitory activity of serotonergic neurons of the raphe nucleus on the mesocortical dopaminergic pathway (Fallisi et al. 2014). On the other hand, simply put, the presence of a psychiatric disorder is a determinant factor for the increase in bruxism and does not depend on the influence of drugs on the CNS. These observations support that idea that the central mechanism of bruxism in bipolar patients may not be similar to that which occurs in normal individuals.

Bruxism can be SSRI related or be due to drugdrug interaction in this group because; the bruxism rates in the polypharmacy group are higher than the 
MS and AAP groups and there is the possibility that the TAP and DAPs that are used heavily in this group may have increased bruxism through nigrostiriatal dopamine pathway (Chen et al. 2005). In addition to this, there is the realization of the possibility that the extrapyramidal side effects are seen by greater rates when TAP and AAP are used in combination in contrast to when they are used separately (Lelliott et al. 2002). Also, there is the possibility that there is a causal relationship between the serotonergic neurotransmission and bruxism symptoms (Lavigne \& Montplaisir 1995).

\section{CONCLUSION}

As a result, the following factors have rendered it difficult to make a clear assessment about the results in this study; having a wide array of psychotropic medications in several different combinations in the treatment protocols of the patient group, small number of cases, lack of similar studies and the inability to conduct analyses in bruxism regarding dose-response relations. In addition to this, the results of this study should be held in high regard considering it is one of the few studies that assesses the interaction of bruxism with psychotropic drugs and supports the therapeutic effect of atypical antipsychotics. However, there is need for further studies that assess the different ways that bruxism can be manifested in bipolar patients over different pathways, in order to uncover the etiology and the details of the relation.

\section{Acknowledgements: None.}

\section{Conflict of interest: None to declare.}

\section{Contribution of individual authors:}

Ozlem Gurbuz Oflezer: study design, literature search, data collection, statistical analysis, first draft, manuscript revisions, approval of the final version.

Hakan Bahadır: literature search, data collection, statistical analysis, first draft, manuscript revisions, approval of the final version.

Berna Gökkaya: literature search, statistical analysis, first draft, manuscript revisions, approval of the final version.

Kursat Altinbas: study design, literature search, data collection, statistical analysis, first draft, manuscript revisions, approval of the final version.

\section{References}

1. Chen WH, Lu YC, Lui CC, Liu JS: A proposed mechanism for diurnal/ nocturnal bruxism: hypersensitivity of presynaptic dopamine receptors in the frontal lobe. $J$ Clin Neurosci 2005; 12:161-63

2. Craddock N, Dave 'S, Greening J: Association studies of bipolar disorder Bipolar Disorders 2001; 3:284-98
3. Fallisi G, Rastelli C, Panti F, Maglione H, Quezada Arcega R: Psychotropic drugs and bruxism 2014; 13:1319-26

4. Fountoulakis KN, Vieta E, Sanchez-Moreno J, Kaprinis SG, Goikolea JM, Kaprinis GS: Treatment guidelines for bipolar disorder: A critical review J Affect Disord 2005; 86:1-10

5. Gurbuz O, Altinbas K, Oflezer C, Kurt E, Delice Arslan M: Signs of Bruxism and Tem poromandibular Disorders among Patients with Bipolar Disorder. BalkJ Dent Med 2017; 152-57

6. Kato $T$, Thie $N$, Huynh $N$, Miyawaki S, Lavigne GJ: Topical review: sleep bruxism and the role of peripheral sensory influences. J of Orofacial Pain 2003; 17:191213

7. Kinalski MA, Cadermatori $M G$, Horta BL, Correa MB, Demarco FF, Pereira-Cenci T: Common mental disorders and bruxism in adults: a birth kohort study. $J$ Dent 2019; 83:27-32

8. Lavigne GJ, Kato T, Kolta A, Sessle BJ: Neurobiological mechanisms involved in sleep bruxism. Critical Reviews Oral Biology Med 2003; 14:30-46

9. Lavigne GJ \& Montplaisir JV: Bruxism: Epidemiology, diagnosis, pathophysiology, and pharmacology. In: Fricton JR, Dubner $R$ (eds). Orofacial and Temporomandibular Disorders, 387-404. New York: Raven Press, 1995

10. Lelliott P, Paton C, Harrington M, Konsolaki M, Sensky $T$, Okocha $C$ : The influence of patient variables on polypharmacy and combined high dose of antipsychotic drugs prescribed for inpatients. Psychiatric Bull 2002; 26:411-14

11. Lobbezoo F, Ahlberg J, Glaros AG, Kato T, Koyano K, Lavigne GJ et al: Bruxism defined and graded: an international consensus J Oral Rehabil 2013; 40:2-4

12. Lobbezoo $F$ \& Naeije M: Bruxism is mainly regulated centrally, not peripherally. J Oral Rehabil 2001; 28:1085-91

13. Lobbezoo F, Soucy JP, Hartman NG, Montplaisir JY, Lavigne GJ: Effects of the dopamine D2 receptor agonist bromocriptine on sleep bruxism: report of two singlepatient clinical trials. J Dent Res 1997; 76:1611-15

14. Manfredini D, Landi N, Romagnoli M, Bosco M: Psychic and occlusal factors in bruxers. Aust Dental J 2004a; 49:84-89

15. Manfredini D, Ciapparelli A, Dell'Osso L, Bosco M: Mood disorders in subjects with bruxing behaviour. $J$ Dent 2005; 33:485-90

16. Mc Meekin H: Treatment of bipolar disorder, restless legs syndrome and parkinsonian symptoms using lamotrigine: a report of seven patients. lamotrigine: a report of seven patients. JSC Med Assoc 2007; 103:69-73

17. Meltzer $H Y$ \& Massey $B W$ : The role of serotonin receptors in the action of atypical antipsychotic drugs. Curr Opin Pharmacol 2011; 11:59-67

18. Mendhekar DN \& Andrade C: Antipsychotic induced bruxism treated with clozapine. J Neuropsychiatry Clin Neurosci 2009; 10:671-72

19. Morgan JC \& Sethi KD: Drug-induced tremors. Lancet Neural 2005; 4:866-76

20. Pelayo $R$ \& Yuen K: Pediatric sleep pharmacology. Child Adolesc Psychiatr Clin N Am 2012; 21:861-83 
21. Piccoli L, Besharat LK, Cassetta M, Migliau G, Dicarlo $S$, Pompa G: Tooth wear among patients suffering from mental disorders. Annali di Stomatologia 2014; 2:52-60

22. Sarac Z, Zovko R, Curlin M, Filakovic P: Dental Medlcine And Psychiatry: The Need For Collaboration And Bridging The Professional Gap. Psychiatr Danub 2020 (in press) doi:10.31219/osf. io/a6cyg

23. Shiwach RS \& Woods S: Risperidol and withdrawal bruxism in Lewy body dementia. Int J Geriatr Psychiatry 1998; 13:64-7
24. Su Y \& Sinko PJ: Drug delivery across the blood-brain barrier: why is it difficult? how to measure and improve it? Expert Opin Drug Deliv 2006; 3:419-35

25. Winocur E, Gavish A, Voikovitch $M$, et al: Drugs and bruxism: a critical review. J Orofac Pain 2003; 17:99111

26. Winocur E, Hermesh H, Littner D, Shiloh R, Peleg L, Eli I: Signs of bruxism and temporo mandibular disorders among psychiatric patients Oral Surg Oral Med Oral Pathol Oral Radiol Endod 2007; 103:60-63

Correspondence:

Assoc. Prof. Ozlem Gurbuz Oflezer, MD

Department of Prosthodontics, Ministry of Health of Turkey,

Bahcelievler Oral and Dental Hospital

Ali Riza Efendi Caddesi. Atakoy 2.Kisim M2 Blok 1. Giris D:2 Atakoy, Istanbul, Turkey

E-mail: zlmgrbz@yahoo.com 